\section{Commentary: Winning or losing in neonatal cardiac reimbursement: Depends on your equation}

\author{
Ronald $\mathrm{K}$. Woods, $\mathrm{MD}, \mathrm{PhD},{ }^{\mathrm{a}}$ and \\ Melissa Barber, $\mathrm{MBA}^{\mathrm{b}}$
}

In their article in this issue of the Journal, Woo and Anderson $^{1}$ present results of a theoretical analysis of profitability of neonatal cardiac surgery reimbursed under the All Patients Refined Diagnosis-Related Groups (APR DRG) system. ${ }^{1}$ The senior author (Anderson) graciously talked me through their thought process and methodology (personal communication). I assure you it was complex, sound (to the extent I can judge such things), and extensive. The authors convey 2 messages: higher-risk neonatal cases may actually result in financial loss, and programs with suboptimal outcomes may incorporate this "unexpected" knowledge when deciding whether or not to refer patients elsewhere. I can assure you the authors are patient outcome, value-driven thinkers. They are simply addressing a sensitive real-world issue (money).

My co-author is a business manager and tried to educate me on these issues. I am now infinitely more informed (something about division by zero). Reimbursement under any type of DRG scheme is far more complex than I would have imagined. As can be seen from the authors' figures, base rates are important, but these vary widely depending on the payer and contracts. You then modify this by level of severity and risk of mortality (of secondary diagnosis). In addition, outlier thresholds vary by payer and contract. Those used by the authors seem quite high. What occurs beyond the outlier also depends on the payer and the negotiated

\footnotetext{
From the ${ }^{a}$ Division of Pediatric Cardiothoracic Surgery, Department of Surgery, Herma Heart Institute, Children's Wisconsin, Medical College of Wisconsin, Milwaukee and ${ }^{\text {b}}$ Children's Wisconsin, Milwaukee, Wis.

Disclosures: The authors reported no conflicts of interest.

The Journal policy requires editors and reviewers to disclose conflicts of interest and to decline handling or reviewing manuscripts for which they may have a conflict of interest. The editors and reviewers of this article have no conflicts of interest.

Received for publication March 31, 2020; revisions received March 31, 2020; accepted for publication March 31, 2020; available ahead of print April 13, 2020.

Address for reprints: Ronald K. Woods, MD, PhD, Division of Pediatric Cardiothoracic Surgery, Children's Wisconsin, 9000 W Wisconsin Ave, MS B730, Milwaukee, WI 53226 (E-mail: rwoods@chw.org).

J Thorac Cardiovasc Surg 2020;160:e155

$0022-5223 / \$ 36.00$

Copyright (c) 2020 by The American Association for Thoracic Surgery

https://doi.org/10.1016/j.jtcvs.2020.03.133
}

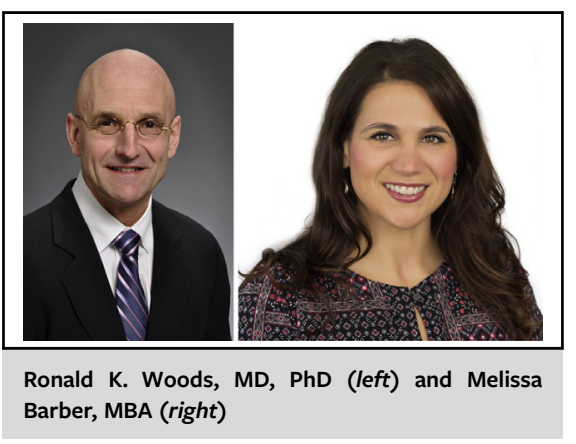

\author{
CENTRAL MESSAGE \\ With diagnosis-related group \\ reimbursement, higher-risk \\ neonatal cardiac surgery could \\ be less profitable or even incur \\ net expense, but this depends on \\ numerous institution-specific \\ factors.
}

contract. For most of our patients, reimbursement occurs on a percentage basis. So it's not as simple as a DRG indicating $\$ X$ reimbursement at the outset, you spend \$Y and gain or lose \$Z. Moreover, in most hospitals, there are many savvy coders who carefully scrutinize the record before coding the primary DRG, as well as astute contract negotiators aware of the service line's ability to provide value with exceptional outcomes.

Keep in mind that this all pertains to the index admission. Survivors remain to generate further hospital visits, studies, possibly more admissions or surgeries - the downstream revenue, a factor the authors did not address. I offer the following real-world equation:

$$
\begin{aligned}
\mathrm{V}(\text { alue }) \text { of } \mathrm{P}(\text { atient }) \text { to } \mathrm{S}(\mathrm{ystem}) & =\mathrm{Xv}(\text { ague }) \\
& + \text { reimbursement } \\
& - \text { expense. }
\end{aligned}
$$

For a children's hospital, the VPS is computed for at least the first 18 years of the patient's life. Xv is a mysterious collection of factors that defy quantification but are very important: keeping the patient close to home, prestige, and benefit to other specialties, among several others. A large Xv could easily compensate for a big financial loss. As for a computation in the neonatal period, forget it. And what about "suboptimal" outcomes? Unless the 
program has very high volume, the precision estimates are typically wide enough for any type of argument to be made.

Yes, a hospital could lose money on higher-risk, higher-resource consuming admissions/cases under a DRG reimbursement system; this would depend on the specific contract and variables therein. I, no doubt like the authors, believe in regionalization and collaboration among programs to provide the best care for our patients. Doing so will likely require an open and honest discussion of Xv.

\section{Reference}

1. Woo JL, Anderson BR. Administrators: do you know how your pediatric cardiac surgeries are reimbursed? J Thorac Cardiovasc Surg. 2020;160:e153-4.
See Article page e153.

\section{Commentary: Reimbursement models in pediatric cardiac surgery: The unrefined All Patient Refined Diagnosis-Related Group}

Tara Karamlou, MD, MSc, ${ }^{2}$ Hani K. Najm, MSD, MSc, ${ }^{\mathrm{a}}$ and Lars G. Svensson, MD, $\mathrm{PhD}^{\mathrm{b}}$

The brief report from Woo and Anderson ${ }^{1}$ in this issue of the Journal aims to put some objective data around the notion of profitability, expense, and how the current All Patient Refined Diagnosis-Related Group (APR-DRG) payment system may not reward institutions adequately for highcomplexity cardiac surgery among neonates. The financial analysis was well conceived (although perhaps incompletely explained) and, in a nutshell, demonstrated lower profitability ratios for cardiac surgery cases compared with noncardiac surgery cases. Reimbursement discrepancies were magnified for high-complexity cases as defined by those cases included in Risk-Adjusted Classification for Congenital Heart Surgery 1 levels 5 and $6 .^{2}$ In the wake of the Coronavirus Disease 2019 pandemic, federal and state

From the Divisions of ${ }^{\mathrm{a}}$ Pediatric Cardiac Surgery and ${ }^{\mathrm{b}}$ Cardiothoracic Surgery, Heart, Vascular and Thoracic Institute, Cleveland Clinic, Cleveland, Ohio.

Disclosures: The authors reported no conflicts of interest.

The Journal policy requires editors and reviewers to disclose conflicts of interest and to decline handling or reviewing manuscripts for which they may have a conflict of interest. The editors and reviewers of this article have no conflicts of interest.

Received for publication April 14, 2020; revisions received April 14, 2020; accepted for publication April 15, 2020; available ahead of print May 5, 2020.

Address for reprints: Tara Karamlou, MD, MSc, Cleveland Clinic Children's Hospital, 9500 Euclid Ave, M41-022A, Cleveland, OH 44195 (E-mail: karamlt@ccf. org).

J Thorac Cardiovasc Surg 2020;160:e156-8

0022-5223/\$36.00

Copyright (c) 2020 by The American Association for Thoracic Surgery

https://doi.org/10.1016/j.jtcvs.2020.04.114
Check for updates

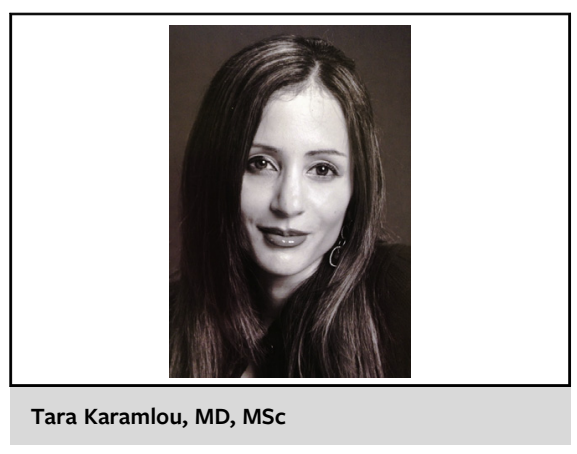

CENTRAL MESSAGE

Current reimbursement models, such as the APR-DRG, for pediatric cardiac surgery are imperfect and may not adequately reward high-complexity neonatal care.

initiatives to ensure financial viability of healthcare organizations and maintain a robust, highly trained physician workforce will be prioritized. An important formative step to the achievement of more stable healthcare delivery systems is the development of thoughtful reimbursement paradigms that are aligned with patient socioeconomic conditions, projected service-line expenses, and locoregional resources. Although Woo and Anderson ${ }^{1}$ do not directly suggest the need for payment model reform, the data presented clearly illustrate the inequities and limitations of the current APR-DRG system.

The APR-DRG system is the most widely used reimbursement model in children's hospitals and categorizes patients according to similar clinical attributes. ${ }^{3}$ In this system, all neonates undergoing cardiac surgery who do not require extracorporeal membrane oxygenation are grouped into just 3 Diagnosis-Related Groups (DRGs) 